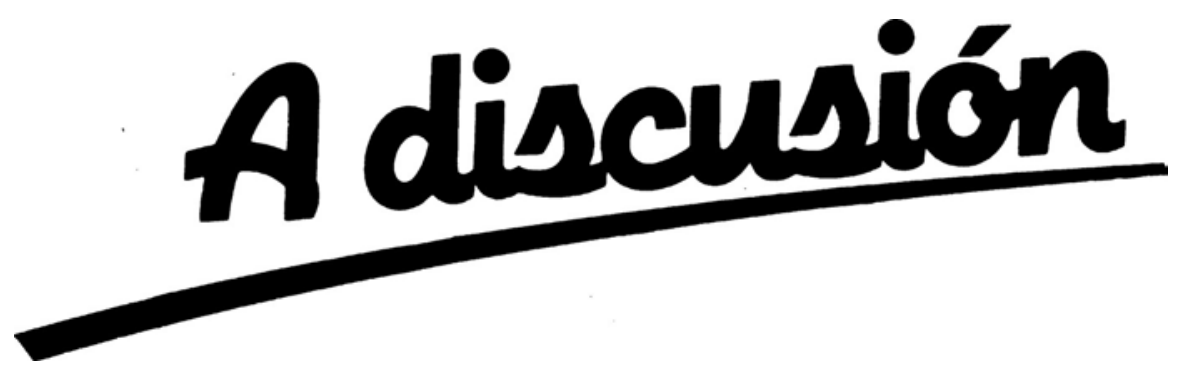

\title{
THE VALUATION OF NON-MONETARY CONSUMPTION IN HOUSEHOLD SURVEYS ${ }^{*}$
}

\section{Christophe Muller}

WP-AD 2004-10

Correspondence to: Christophe Muller, Universidad de Alicante, Dpto. Fundamentos del Análisis Económico, Campus de San Vicente, 03071 Alicante, Spain,. Fax: +34 965903898 / E-mail: cmuller@merlin.fae.ua.es.

Editor: Instituto Valenciano de Investigaciones Económicas, S.A.

Primera Edición Marzo 2004.

Depósito Legal: V-1623-2004

IVIE working papers offer in advance the results of economic research under way in order to encourage a discussion process before sending them to scientific journals for their final publication.

\footnotetext{
* I acknowledge a TMR grant from the European Union. I am grateful to the Ministry of Planning of Rwanda which provided me with the data, and in which I worked from 1984 to 1988 as a technical adviser from the French Cooperation and Development Ministry.
} 


\title{
THE VALUATION OF NON-MONETARY CONSUMPTION IN HOUSEHOLD SURVEYS
}

\author{
Christophe Muller
}

\begin{abstract}
Many social indicators are based on household consumption information. The valuation of non-monetary operations is crucial for the analysis of consumption surveys in developing countries because of the importance of own-consumption and transfers in kind. What are the price statistics used in the valuation of consumption indicators? How is the available price information exploited to produce consumption indicators? How can the different steps of the valuation process be analysed? We explore these questions by presenting the valuation method for the consumption used in rural Rwanda for the 1983 consumption survey, and by proposing a general model of valuation algorithm. This is useful not only for improving such algorithms, but also for assessing the impact of the valuation process on economic analyses.
\end{abstract}

Keywords: Household surveys, Data processing, Consumption analysis, Valuation method, Prices, Demand Systems, Poverty Analysis. 


\section{Introduction}

Many social indicators are based on household consumption information. Consumption surveys (CS) are the main information source about household consumption. Numerous CS have been implemented since the ninetieth century ${ }^{1}$ in Europe and since the beginning of the twentieth century ${ }^{2}$ in less developed countries. Producing high quality economic indicators from CS is important for both statisticians and economists ${ }^{3}$ because biases intervening during the calculus of consumption indicators may be more serious than the ones occurring in data analysis.

Although numerous authors have discussed the design of $\mathrm{CS}^{4}$, little interest has been devoted to the valuation of non-monetary consumption. Though, this valuation is of considerable interest as such consumption can be a significant share of consumption of poor rural households. In many LDCs (Less Developed Countries), especially in rural areas, ownconsumption rates (ratios of produced consumption over total consumption) can be very high, and gifts and other transfers in kind very common. For example, the average ownconsumption rate in 1983 (proportion of consumption coming from own production) in rural Rwanda is above $66 \%$ overall and almost $80 \%$ for food (from our own estimates using the National Budget-Consumption Survey 1983 in Muller 1992). In these conditions, the valuation method of consumption records is crucial to the measurement of aggregate household consumption in LDCs. However, in the absence of precise description of the valuation process, it is hard to understand its nature and its impact on economic analyses.

What are the price statistics used for the valuation of consumption in consumer surveys? How can the steps of the valuation process be analysed? Which lessons can be drawn for economic analyses? The aim of this article is to explore these questions first by presenting the valuation method that was used in rural Rwanda for the CS conducted in 1983 (denoted CSR83), then by proposing a model of valuation algorithm. This novel approach is useful not only for improving such algorithms, but also for assessing the impact of the valuation process on economic analyses. In Section 2, we present the valuation algorithm and

\footnotetext{
${ }^{1}$ Williams and Zimmerman (1935).

${ }^{2}$ Descriptions of typical CS are available in OCDE (1978), Scott, de Andre and Chander (1980), Booker, Singh and Savane (1980), Wahab (1980), Grootaert (1985), Grosh and Munoz (1996).

${ }^{3}$ Bailar (1985), Philipson (1997).

${ }^{4}$ Chevry (1962), Winter (1970), Verneuil (1983), United Nations (1983, 1989), Casley and Lury (1987), Morgan (1987), Blaizeau and Dubois (1989), Biemer et al. (1991), Grosh and Munoz (1996).
} 
the price indicators that have been used for CSR83. In Section 3, we analyse the different stages of a general valuation algorithm for a CS. Finally, we conclude in Section 4.

\section{The Valuation of Consumption in a Consumption Survey}

\subsection{Origin of the Price Information}

It seems a good idea to start by looking at where does the price information come from. The two main sources of prices for valuation algorithms are: price surveys in markets, and the CS itself from the records of value and quantity for purchases or sales. These two sources have different advantages. Price surveys provide price information less dependent on household tastes and purchasing power because of a better control of quality choices. However, since price observations are collected only in selected sites, they may provide inaccurate estimates of the prices with which some households are confronted. Moreover, the wording of the questions, and more generally the collection method of prices, are always debatable in that they constitute artificial observation situations, different from what occurs during actual transactions. Finally, it is never possible to obtain price observations for every good in every selected market or transaction site. This implies that the treatment of missing values for prices is an important stage of using market price data. Furthermore, even when price observations are available, the analyst is not content to use them if they are isolated. Large samples of price observations are in fact necessary and what is called "market price" in the price file used for the valuation is generally a central tendency of this sample distribution, the mean or the median of observed prices.

On the other hand, when budget data are used to calculate prices, the information about prices fits household consumption patterns more closely. Indeed, goods that are usually consumed in an area appear in records of local purchases or sales, even when they are only consumed in kind (from their own production or received as gift) by some of the households of this area. This significantly contributes towards solving the problem of missing price data. The prices extracted from a budget survey are in fact unit-values, i.e. ratios of values over quantity extracted from observations of the individual transactions. The most appropriate transactions for this calculus are the consumption purchases, and the production sales. This leads to elementary unit-value observations that can be interpreted respectively as "consumption prices" and "production prices". Other transactions are generally not associated with large enough samples of observations to be of great use. 
Unfortunately, other difficulties arise. Elementary unit-values are affected by choices of qualities by consumers or sellers. This problem is much less serious than for unit-values calculated from broad categories of consumption (as in Deaton, 1988, 1990) where similar goods are aggregated in a common category (for example "fish"). In the latter case, the unitvalues calculated from these aggregate values and quantities are clearly different from observed prices in a market (e.g. price of a specific fish). However, quality bias occurring with elementary unit-values would arise from differences in actual quality between two units of the same elementary product, for example "Tilapia", a species of fish. Even if one expects it to be relatively minor, the quality choice problem remains.

Another problem is that elementary unit-values may be affected by measurement errors occurring in value and quantity observations. In that situation, the measure provided by elementary unit-values may not be accurate enough to validly approximate actual market prices. The endogeneity of unit-values can be treated by using a prediction model for prices or merely by using means of prices, at the cluster or at the regional level. Indeed, providing the size of the unit-value sample is large enough, aggregate means discard most endogeneity problems associated with a specific household that contributes only to a negligible fraction of the mean. These procedures do not eliminate endogeneity arising at a regional level, for example high prices reflecting a high quality of consumption related to the general wealth in this region or to regional tastes. However, this difficulty is also present with market prices. Aggregate means of unit-values also provide estimates of prices based on large samples and thus eliminate much noise in price observations and part of missing value problems. The type and the aggregation levels for the price means are to be selected for the valuation algorithm. We now turn to the specific example of CSR83.

\subsection{An Example of Survey}

The Rwandan national budget-consumption survey was conducted by the government of Rwanda and the French Cooperation and Development Ministry, in the rural part of the

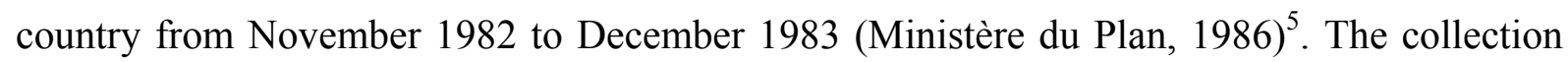
of the consumption data was organised in four rounds, roughly corresponding to quarters ${ }^{6}$. During these rounds, 270 households were surveyed about their budget and their consumption. Every household was visited at least once a day during two weeks for every

\footnotetext{
${ }^{5}$ The main part of the collection was designed with the help of INSEE (French National Statistical Institute). The author was himself involved in this project as a technical adviser from the French Cooperation and Development Ministry.

${ }^{6}$ Their dates are Round A from 01/11/1982 to 16/01/1983; Round B from 29/01/1983 to 01/05/1983; Round C from $08 / 05 / 1983$ to $07 / 08 / 1983$; Round D from $14 / 08 / 1983$ to $13 / 11 / 1983$.
} 
quarter. The consumption was systematically recorded with daily and retrospective interviews, and all food was weighed. Every household also had to record budget information in a diary between the quarterly survey rounds.

Let us examine in the CSR83, the questionnaires from which price and consumption information can be extracted. They are the following ones.

Q4: Daily transactions. This questionnaire is filled every day during 14 days of every quarter for each household of the core sample (270 households). The collection is based on daily interviews.

Q2: Retrospective transactions. This questionnaire is filled in every quarter for each household of the global sample (1170 households). The collection is based on retrospective interviews and diaries with a three-month recall.

Q5: Food consumption. This questionnaire is filled every day for seven days of every quarter for each household of the core sample. The collection is based on daily weighing of the food and daily interviews.

Q7: Price survey in markets. This questionnaire is filled every week when households are visited in the same sector. The collection is based on interviews of sellers in markets and in other transaction sites, and weighing of the products.

The questionnaires are simultaneously the source of the price information and the location of consumption records to value. We shall describe the valuation process for the CSR83 in three steps: definition of price indicators, comparison of price means, and valuation algorithm. This illustration based on CSR83 will suggest the general model in Section 3.

Before examining the price indicator, we need to identify the records to value. Different types of records are to be valued: barter, received and offered gifts, food consumption measures based on direct weighing (purchased, received as gift, taken from stocks), quantities of food own-consumption weighed before the meals. The identification of the records that need to be valued in every questionnaire file indicates the products for which we need price indicators for the valuation.

The next step consists in creating a price file to organise the set of price observations. There are three types of prices in the file: (1) the production prices that are ratios of the recorded value of output sales by the recorded quantity sold; (2) the consumption prices that are ratios of the recorded value of consumption expenses by the recorded quantity bought; (3) the direct measurement of prices in markets. Let us describe more precisely how these different price statistics are calculated. 
The consumption prices (PC1 and PC2) are calculated using data from questionnaire Q4 (daily transactions), which is the most accurate source of budget information. Prices PC1 are calculated using records of consumption purchases, prices PC2 using records of production sales to another person likely to consume the product of interest. The production prices (PP1 and PP2) are also calculated using data from questionnaire Q4. Prices PP2 are based on records of production sales, while prices PP1 are calculated using records of consumption purchases from a peasant selling his own production. Finally, the market prices (PM) are calculated using data from questionnaire Q7. We use only prices PC1, PP2 and PM for which we have significant sample sizes. From now we denote PC1 as PC and PP2 as PP.

Based on these three types of prices, the valuation system is organised in three geographical levels (local, regional, national) and two temporal levels (quarter and year). Rwanda is divided into 10 prefectures and 143 rural communes, although only 90 communes had been selected in the sampling scheme. Rwanda is also divided into 5 agricultural zones, called "regions" here, which are defined on the basis of their agro-ecological characteristics.

At all these geographical and temporal levels, we calculate price means for each type of price (PC, PP, PM) and each product. We weigh the price means using the sampling weights and the average consumption (or production) shares of households in the relevant geographical and temporal units. The price means are calculated for the temporal levels: year and quarter, and the geographical levels: the whole country, the prefecture, the region, and the commune. This yields 8 possible combinations of levels. Using the regions rather than the prefectures has several advantages. First, the regions have clear economic and agricultural meaning and then the corresponding price samples are more likely to be homogeneous. Second, the sizes of price samples on which the means are calculated are larger.

The obtained price means for the different aggregate levels are available for more than one hundred products. In total almost 24,000 price statistics are available. Table 1 presents the distribution of price mean records across the categories of means. No one category of price means accounts for a substantial part of these records. The main category is composed of the means of PC prices at the levels of commune and quarter, with 17.7 percent of the price records. The means of PC prices at the levels of prefecture and year, and the means of PM prices at the levels of commune and quarter are also important with respectively 10.6 percent and 10.0 percent of the records. The majority (54.1 percent) of price means are of PC type, the remainder being shared between PM type (27.5 percent) and PP type (18.4 percent). About two thirds (65.4 percent) of the price means are at the quarterly level. Almost half (45.4 percent) of the price means are at the commune level, while only 7.7 percent are at the national level. The reason why quarterly and commune levels are not overwhelmingly dominant in this file is that price means have been rejected from the data base when the 
Table 1. Distribution of the records of the price database across categories of price means

\begin{tabular}{lccccc}
\hline & & $\mathbf{N}$ & $\mathbf{C}$ & $\mathbf{P}$ & $\mathbf{Z}$ \\
\hline & & & & & \\
& $\mathrm{PC}$ & 251 & 1004 & 2526 & 700 \\
& & $(1.1)$ & $(4.2)$ & $(10.6)$ & $(2.9)$ \\
& $\mathrm{Q}$ & 635 & 4226 & 2021 & 1513 \\
& & $(2.7)$ & $(17.7)$ & $(8.5)$ & $(6.4)$ \\
$\mathbf{P M}$ & $\mathrm{A}$ & 134 & 1270 & 441 & 324 \\
& & $(0.6)$ & $(5.3)$ & $(1.9)$ & $(1.4)$ \\
& & & & & \\
& $\mathrm{Q}$ & 331 & 2374 & 962 & 723 \\
& & $(1.4)$ & $(10.0)$ & $(4.0)$ & $(3.0)$ \\
$\mathbf{P P}$ & $\mathrm{A}$ & 154 & 753 & 390 & 296 \\
& & $(0.6)$ & $(3.2)$ & $(1.6)$ & $(1.2)$ \\
& & & & & \\
& $\mathrm{Q}$ & 317 & 1176 & 721 & 570 \\
& & $(1.3)$ & $(4.96)$ & $(3.0)$ & $(2.4)$ \\
Total & 23812 & & & & \\
& $(100)$ & & & & \\
\hline & & & & &
\end{tabular}

The first number in each cell is the number of records. The number in parenthesis is the percentage.

The categories of the price means are composed of three elements: the type of price (PC, PM, PP); the geographical level $(\mathrm{N}=$ national, $\mathrm{C}=$ communal, $\mathrm{P}=$ prefecture, $\mathrm{Z}=$ regional $)$, the temporal level $(\mathrm{A}=$ annual, $\mathrm{Q}=$ quarterly $)$.

Frequencies of mean prices by: 1. Price type; 2. Temporal level; 3. Geographical level.

\begin{tabular}{cccccc}
\hline 1: Price type & $\%$ & $\begin{array}{c}\text { 2: Temporal } \\
\text { level }\end{array}$ & $\mathbf{\%}$ & $\begin{array}{c}\text { 3: Geographical } \\
\text { level }\end{array}$ & \% \\
\hline PC & 54.1 & $\mathrm{~A}$ & 34.6 & $\mathrm{~N}$ & 7.7 \\
$\mathrm{PM}$ & 27.5 & $\mathrm{Q}$ & 65.4 & $\mathrm{C}$ & 45.4 \\
$\mathrm{PP}$ & 18.4 & & & $\mathrm{P}$ & 29.7 \\
& & & & $\mathrm{Z}$ & 17.3 \\
\hline
\end{tabular}

sample of price records at the considered levels was judged too small to be reliable. At least ten observations of prices of good quality, and generally more, were required to accept the mean price calculated at the communal quarterly level. Using data from a national CS in Tunisia, Ayadi and Muller (2003), show that measurement errors are important in unit-value data. Relying on mean or median of several observations of unit-values is a simple way to overcome most of this issue. This is also a rather efficient way of getting rid of the influence 
of quality choices. This approach is to be opposed with the common use of unit-values at the household level that have been shown to be highly sensitive to measurement errors and endogenous quality choices.

Beyond this general picture, it is illuminating to focus on a few main products to study the orderings of the price means for the three types of prices. Twenty-two main products have been selected. The most important ones are: sorghum, sweet cassava, rice, sweet potatoes, potatoes, beans, aubergines, palm oil, salt, banana beer, sorghum beer, soap and cigarettes. A specific variety of the product is used when collecting its price. Table 2 shows the distribution of orderings of the types of national price means for these products by quarter. Only means based on a large number of observations have been kept, which explains different totals at different quarters. PP means are always inferior to the corresponding PC means and this comparison is not included in the table. PM means are always greater than the corresponding PP means except on one occasion. The national production prices can therefore be considered as almost systematically inferior to consumption prices and market prices, which seems natural because of transport, transaction and intermediation costs. Therefore, production prices should be avoided when possible for the valuation of consumption from a consumer perspective. The situation is less clear when comparing PM and PC means. At the national and quarterly levels, their ordering is rather indifferent. Further analysis at more disaggregate levels have shown us that PC and PM prices are actually very similar. This suggests that the endogeneity problems related to PC prices, which could arise at the household level, do not raise serious concern for price means calculated at the commune level.

Table 2. Distribution of the main products by ordering of price means and by quarter

\begin{tabular}{lcccc}
\hline Ordering & Quarter A & Quarter B & Quarter C & Quarter D \\
\hline $\mathrm{PM}>\mathrm{PP} 2$ & 9 & 8 & 7 & 10 \\
$\mathrm{PM}<\mathrm{PP} 2$ & 0 & 1 & 0 & 0 \\
$\mathrm{PM}<\mathrm{PC} 1$ & 4 & 7 & 7 & 5 \\
$\mathrm{PM}>\mathrm{PC} 1$ & 7 & 4 & 5 & 7 \\
\hline
\end{tabular}

We now turn to the way we rank these price means before to incorporate them in the valuation algorithm. The same valuation algorithm is used to value barter, non-purchased gifts, and food own-consumption. One must also use the same valuation algorithm for the received gifts and the offered gifts, in order to be able to consistently compare these different flows. To be able to order the different price means for each product, we compare them at 
different aggregation levels. These investigations mix statistical analyses and expert judgement, the latter based to a large extent on the knowledge of enumerators. The first column in Table 3 shows the obtained preference ordering for the different types of price means.

Table 3. Results of the Valuation Algorithm for the Non-Monetary Consumption

\begin{tabular}{lcc}
\hline Type of price mean used for valuation & $\begin{array}{c}\text { \% of the value of } \\
\text { non-monetary } \\
\text { consumption }\end{array}$ & $\begin{array}{c}\text { \% of food weight of } \\
\text { non-monetary food } \\
\text { consumption }\end{array}$ \\
\hline 1 & 3.87 & 3.07 \\
2 & 34.18 & 29.11 \\
3 & 15.12 & 38.50 \\
4 & 6.41 & 4.41 \\
5 & 15.43 & 6.87 \\
6 & 18.87 & 9.96 \\
7 & 0.01 & 0.02 \\
8 & 0.85 & 0.26 \\
\hline 9 & 2.05 & 1.49 \\
\hline 10 & 0.49 & 1.33 \\
\hline 11 & 2.72 & 4.97 \\
\hline
\end{tabular}

1. Mean consumption price for the same cluster and the same quarter.

2. Mean consumption price for the same quarter and the same region.

3. Mean market price for the same quarter and the same region.

4. Mean consumption price for the same quarter and the same region.

5. Mean consumption price for the same quarter and the whole country.

6. Mean market price for the whole year and the whole country.

7. Mean production price for the whole year and the whole country.

8. Mean consumption price for the whole year and the whole country and with a small number of price observations (less than 10).

9. Mean consumption price for the whole year and the whole country and with a very small number of price observations (less than 5).

10. Mean market price for the whole year and the whole country and with a very small number of price observations (less than 5).

11. Price coming from a source external to the survey. 
This ordering of the price means is important because it determines how every consumption record in the questionnaire files is valued. When a desired price mean is not available at a given level for the considered product and geographical and temporal levels, the algorithm searches for a mean price at the next level. We believe that the best price mean, corresponds to the cluster and the quarter where the consumption quantity has been recorded because of the proximity of the actual place and time at which this consumption could have been purchased. However, using this preferred price mean is not always possible because only price means based on large enough samples of observed prices are kept. In a sense, we assume that the accuracy of the price means for our purpose mostly depends on its temporal and geographical proximity with the consumption observations. Another approach would have been to consider the trade-off between the higher variance of the conceptually correct price (from the same locality and quarter) against the bias of having a price that is from a larger region (but has a lower variance), rather than just using the criterion of the sample size. We did not retain it here because the valuation operations had to be performed by agents not ttrained in statistics.

Once the ranking of the price means is ready, we apply the corresponding algorithm to our consumption survey. Table 3 shows how the non-monetary consumption records in CSR83 are valued. The optimal price means (that of PC type at communal quarterly level) are only used for three percent of the non-monetary consumption value because for many products the sample of observed prices on which are based these price means is judged too small. Using then much more often would introduce massive data contamination. The main price means for the valuation are the quarterly regional PC means that are used for about one third of the valued non-monetary consumption. Then, the PM means at the annual national level, the quarterly national PC means and the quarterly regional PM means are the other major instruments for the valuation. The other price means are less useful. In particular, production prices almost never need to be used. On the whole, almost 60 percent of the nonmonetary consumption are valued with quarterly price indicators at local or regional level. The breakdown of the valuation of food non-monetary consumption by food weight provides a similar picture, showing that the price levels of different products affect, but do not massively distort the decomposition of the valuation. The results imply that for this survey the valuation of non-monetary consumption can be reasonably accurate. Such result was not obvious a priori and may not be verified for all consumption surveys. Moreover, the valuation process appears to be more complex than is generally expected in consumer studies. It does not correspond to the simple picture presented in economic theory, or even in applied economic studies.

Naturally, examples based on other consumption surveys would deliver different results. However, the valuation procedures in such surveys are of similar nature and therefore 
raise the same type of issues. Let us now draw the lessons of the CSR83 by systematising the valuation process in a general algorithm valid for most consumption surveys.

\section{A General Valuation Algorithm}

What we propose is a conceptual pattern for the valuation process. This pattern is useful on several grounds: (1) it eases the replication of valuation operations in different CS; (2) it facilitates the design of valuation algorithms; (3) it clarifies the resources to allot to this operation; (4) it distinguishes the tasks involved in the design and the execution of the valuation; and finally (5) it guides the specification of optimality criteria for the valuation operations.

The conceptual framework will be all the more useful if the different stages of the valuation algorithm can be incorporated in the design of a data base management system. In that case, a change in the valuation rules or in the sample of price means could be easily incorporated so as to update the consumption indicators. Moreover, the price data set could be included in the survey database. This would enable analysts to use it for aims other than the consumption valuation. In this regard, the sorting variables used for the price data set and for the algorithm must be carefully designed. For each product, three natural sorting variables are (a) the type of prices (PC, PP or PM in the example); (b) the geographical unit; (c) the temporal unit. We are now ready to describe the algorithm.

We propose a model of valuation algorithm in seven steps: (1) Selection of records to value in the questionnaire files; (2) Confection of samples of elementary price indicators; (3) Calculus of price means at the different geographical and temporal levels and by type of price; (4) Choice of the optimal price mean indicator; (5) Establishment of a proximity map for the different price mean indicators; (6) Ordering of the different price mean indicators; (7) Execution of the valuation.

We now discuss the decision rules applied to each of these steps.

Step 1 (records to value). The rules are semantic here and must correspond to the economic operations for which the valuation is desired. In our example, the rules select in questionnaire files the records that are own-consumption, gifts received in kind, consumed results of barter, and consumption taken from stocks. The selection rule for a questionnaire therefore corresponds to a product of sets $\left(A_{1} \times \ldots \times A_{s}\right)$, each set $A_{i}$ describing a list of codes for a selection variable. For example, for some records one can use the following product of code sets: \{codes of uses corresponding to consumption of the transacted product\} $\mathrm{x}$ \{codes of 
transaction types that correspond to transfer received in kind (among other non-monetary consumptions $\} \times$ \{codes of the products that are consumable $\}$ x \{missing value for the recorded value of the transaction (indicating that it remains to value) $\}$.

Step 2 (elementary prices). The rules are semantic and economic. They correspond to selections of records similar to Step 1. However, here the selected records are characterised by:

(A) no missing values for the variables cluster, round, product, measurement unit, quantity, and value.

(B) specific transactions that correspond to: monetary consumption expenses, monetary production sales, direct collection of prices at transaction sites. Again, the selection rule is a product of sets $\left(\mathrm{B}_{1} \mathrm{x} \ldots \mathrm{x} \mathrm{B}_{\mathrm{s}}\right)$, each set $\mathrm{B}_{\mathrm{i}}$ describing a list of codes admissible for a variable. Particularly useful are codes related to the following variables: use of the transacted product, transaction type (expenses, sales, transfers...), transaction partner, transaction location.

(C) an a priori interval of admissible prices that can be defined for each product. Indeed, enumerators and price analysts are expert enough to be able to eliminate many errors and aberrant price values at this stage. Finally, the considered unit-value (i.e. value divided by quantity) is calculated for each recorded transaction, and is stored in a temporary price data set, with indexation by its level (price type, geographical unit, temporal unit). The observations of the market prices are directly stored.

Step 3 (price means). The rules are statistical. Means, standard deviations and sample sizes of selected sets of price records in the price data set are calculated for each level. The statistics may or may not be weighed by using the sampling scheme and observed consumption (or production) levels. Only the price means considered close enough to the actual (but unobserved) price mean are inserted in the price means database. Statistical tests such as Student tests of differences of means can be used to guide this decision.

Step 4 (optimal price mean). The rule is economic. If the statistical rules applied in Step 3 are judged sufficient to ensure the overall reliability of the set of price means in the data base, then it is natural to decide that the optimal price means to use first are the ones from whichever level is the closest to the consumption record to value. Since the notion of level is composite, there may be several optimal price mean indicators. In that case, a loss function can be used to calculate the risk of different alternatives. In our previous example, the optimal price mean indicator is the quarterly communal consumption price. 
Step 5 (proximity map). The rules are topological. A proximity measure is chosen to represent the relative positions of the different sets of price means. A simple solution is to consider that the set of price means at the most disaggregate level is a vector of which dimension is the number of price means at this level. For example, in CSR83, the vector of the $\mathrm{PC}$ means of a given product at the quarterly communal level, denoted $\mathrm{PC} \mathrm{CQ}_{\mathrm{CQ}}$, would have 4 (the number of quarter) by 90 (the number of communes), i.e. 360 components. Then, a set of price means of a more aggregate level can be described by a vector of same dimension by replication of the price means in all sub-levels. For example, the vector of annual regional means of consumption prices in CSR83, denoted $\mathrm{PC}_{\mathrm{ZA}}$, would also have 360 components, each couple (commune, quarter) being affected with the annual price mean for the region to which the considered commune belongs. Then, one can calculate a distance between these vectors. For example, the Euclidean distance between $P C_{C Q}$ and $P C_{Z A}$ can be defined as

$$
d\left(P C_{C Q}, P C_{Z A}\right)=\left[\sum_{i} \sum_{j} \sum_{q}\left(P C_{j, q}-P C_{i, A}\right)^{2}\right]^{1 / 2}
$$

where $i$ denotes the index of regions, $j$ is the index of the communes in Region $i, q$ is the index of quarters, $P C_{j, q}$ is the mean consumption price for Commune $j$ at Quarter $q$, and $P C_{i, A}$ is the mean consumption price for Region $i$ at annual level. More sophisticated distance functions involving the empirical variances and covariances of the price indicators are also interesting. In any case, such approach implies that the observed proximity is considered to be good indicators of the actual proximity.

Step 6 (ordering of price means). The rules are quasi-orderings. Since one optimal set of price means has been chosen in Step 4, a natural ordering can be deduced from the relative proximity of sets of price means to this optimal set. The distance defined in Step 5 can be used for this purpose. However, other considerations may suggest different orderings. Thus, one component of the level might be of special importance. For example, one may want to use prices of the same quarter to avoid incorporating effects of seasonal fluctuations in the calculus of consumption indicators, perhaps because one aim of the consumption analysis would be to study its seasonality. In that case, price means with a value of this special component common with the optimal set will be ordered at a higher level than other price means. Here, the final use of consumption indicators is important in determining the ordering of price means.

Step 7 (valuation). The rules are logical selections. Once the ordering of sets of price means designed in Step 6 is ready, it is easy to define the execution process of the valuation.

Table 4 summarises some possible effects of the different steps of the valuation process on three types of economic analyses: aggregate consumption analyses, living standard 
distribution analyses, and household behaviour models. These reflections can be summarised in three levels. Firstly, the valuation procedure affects the accuracy of consumption indicators and living standard indicators, at the aggregate level as at the individual level. Notably, the selection of records to value determines the coverage of these indicators. Assuming that all possible consumption quantities have been observed does not imply that all these records must be valued and used for the economic analyses, if the available price information is too mediocre to yield credible numbers. Another danger for the accuracy of indicators is the occurrence of measurement errors coming from using imperfect and imprecise combinations of price type, and geometrical and temporal levels for organising the price information. Other measurement error for these indicators, and the macroeconomic variables calculated from this information arise from the inaccuracy of the proximity map and of the ordering of price means.

Table 4. Consequences for economic analyses of the steps of the valuation algorithm

\begin{tabular}{|c|c|c|c|}
\hline Steps of the algorithm: & $\begin{array}{l}\text { Aggregate consumption } \\
\text { analyses }\end{array}$ & $\begin{array}{l}\text { Living standard } \\
\text { distribution analyses }\end{array}$ & $\begin{array}{l}\text { Estimates of consumer } \\
\text { demand systems and other } \\
\text { household behaviour } \\
\text { models }\end{array}$ \\
\hline $\begin{array}{l}1 . \text { Selection of records to } \\
\text { value }\end{array}$ & $\begin{array}{l}\text { Scope of possible analyses } \\
\text { based on values of aggregate } \\
\text { variables. }\end{array}$ & $\begin{array}{l}\text { Coverage of living standard } \\
\text { variables. }\end{array}$ & $\begin{array}{l}\text { Scope of behaviour studies } \\
\text { based on market hypotheses. }\end{array}$ \\
\hline $\begin{array}{l}\text { 2. Samples of elementary } \\
\text { prices }\end{array}$ & $\begin{array}{l}\text { Respect of valuation } \\
\text { conventions in national } \\
\text { accounts (production is } \\
\text { valued at producer prices, } \\
\text { consumption at consumer } \\
\text { prices). }\end{array}$ & $\begin{array}{l}\text { Impact of spatial and } \\
\text { temporal distribution of } \\
\text { prices on poverty and } \\
\text { inequality measures, when } \\
\text { using imperfect price indices. }\end{array}$ & $\begin{array}{l}\text { Possibilities of studies of } \\
\text { market imperfections (where } \\
\text { consumer prices, producer } \\
\text { prices and market prices are } \\
\text { different). }\end{array}$ \\
\hline $\begin{array}{l}\text { 3. Prices by type, } \\
\text { geographical and temporal } \\
\text { levels }\end{array}$ & $\begin{array}{l}\text { Aggregation bias and } \\
\text { inaccuracy of aggregate } \\
\text { variables. }\end{array}$ & $\begin{array}{l}\text { Idem as above. } \\
\text { Accuracy of poverty and } \\
\text { inequality measures. }\end{array}$ & $\begin{array}{l}\text { Unit-value biases. } \\
\text { Bias and accuracy of agent's } \\
\text { responses to price } \\
\text { differences. }\end{array}$ \\
\hline $\begin{array}{l}\text { 4. Choice of the optimal } \\
\text { price mean indicator }\end{array}$ & $\begin{array}{l}\text { Consistency with valuation } \\
\text { conventions for national } \\
\text { accounts. } \\
\text { Consistency for budget } \\
\text { balances. }\end{array}$ & $\begin{array}{l}\text { Consistency with welfare } \\
\text { axiomatic (under perfect } \\
\text { markets true price indices are } \\
\text { ratios of cost functions). }\end{array}$ & $\begin{array}{l}\text { Consistency with hypotheses } \\
\text { about agents behaviour and } \\
\text { markets (e.g. consumption } \\
\text { prices are needed for the } \\
\text { basic consumer model). }\end{array}$ \\
\hline $\begin{array}{l}\text { 5. and 6. Proximity map of } \\
\text { price means and ordering of } \\
\text { price means }\end{array}$ & $\begin{array}{l}\text { Size of bias in measured } \\
\text { aggregates as compared with } \\
\text { the true unobserved values of } \\
\text { these aggregates. }\end{array}$ & $\begin{array}{l}\text { Size and direction of bias in } \\
\text { poverty and inequality } \\
\text { estimates. }\end{array}$ & $\begin{array}{l}\text { Unit-values bias. Spatial price } \\
\text { bias. Temporal price bias. }\end{array}$ \\
\hline $\begin{array}{l}\text { 7. Execution of the } \\
\text { valuation }\end{array}$ & $\begin{array}{l}\text { Errors in macroeconomic } \\
\text { aggregates. }\end{array}$ & $\begin{array}{l}\text { Errors in poverty and } \\
\text { inequality statistics. }\end{array}$ & $\begin{array}{l}\text { Errors in parameter estimates } \\
\text { of behaviour models. }\end{array}$ \\
\hline
\end{tabular}

Secondly, the valuation process generates in consistencies with valuation conventions imposed by some economic theories. For example: (1) for national accounting, production is 
valued at 'producer prices' and consumption is valued at 'consumer prices'; (2) in welfare economies, true price indices are often defined as ratios of cost functions representing the agent preferences; (3) perfect markets (and therefore a unique price for a given product) are often assumed in models of consumer demands. Such situation should be taken into account when proceeding with economic analyses.

Finally, the valuation process is likely to influence the results of economic analyses. It is for example the case for the measure of the impact of the spatial and temporal price distribution on poverty and inequality indicators. Clearly, the available imperfect price sample for the valuation may influence the results since price effects may appear at two places: first, in the calculation of consumption indicators; and second in the correction of price differences for living standard indicators. Similarly, when the topic of interest is related to market imperfections, the used consumption levels may partly result from such market imperfections and the use of an inappropriate valuation algorithm. However, the most common problem may be the biases caused in the econometric estimation for (1) microeconomic behaviour models such as demand systems, (2) poverty and inequality analyses, (3) macroeconomic models based on aggregate consumption. Not only the samples of prices used, but also the way they are organised and the ordering of price means may affect the estimation results, to an extent that is unknown. The decomposition of the valuation process should help in developing analyses of the above effects and in improving their control. However, further study would be necessary to analyse the precise effect of the valuation process used in a given survey for a specific type of economic analysis.

\section{Conclusion}

In this paper we first describe the valuation algorithm of the non-monetary consumption that was used for the consumption survey of Rwanda in 1983. The majority of the consumption was valued by using price indicators at local or regional quarterly level, although it was not always possible to discard the use of national or yearly price indicators. The analysis of the valuation for this survey shows that compromises are necessary because the samples of available prices are not ideal. It also shows the type of statistical analyses that need to be carried out to design a performing valuation algorithm.

Then, extrapolating from this experience, we propose an algorithm that systematises the valuation operations for a consumption survey, and that exhibits the different steps and the decision rules used at each step. Our model reveals the rules for: (a) the identification of consumption records to value; (b) the selection of price records to use for the valuation; (c) the confection of a database of price means; (d) the logical ordering of these sets of price 
means. This model should ease the replication of valuation operations in consumption surveys, facilitate the choices for the valuation algorithm, clarify the resources to allot to this operation, help to distinguish the tasks involved in the design and the execution of the valuation, and finally assist in the definition of optimality criteria to judge the quality of the valuation operations.

Usually, the valuation method used in a survey is taken for granted by economists. In contrast, our algorithm shows that the consumption indicators used for macroeconomics, estimation of micro-economic demand systems or welfare analysis, are substantially different from the simplicity assumed by the economic theory. This complexity of actual consumption indicators implies that the valuation process may influence the results of microeconomic and macroeconomic analyses. Therefore, the valuation of non-monetary economic operations is a matter to consider seriously. To dispose of an analytical decomposition of the valuation algorithm should help such control.

Naturally, further investigations would be necessary to deal with a given survey and a specific economic analysis in order to isolate what is important in the data generation process related to valuation for the case of interest. Indeed, what is learned for a specific survey cannot always be directly extrapolated to other surveys. The analytical framework that we presented should help the adaptation to different surveys.

It is also clear that the valuation is important only if non-monetary consumption is substantial. This is the case in many LDCs because of the size of the non-monetary economics in these countries, but also in more developed countries when consumption of goods produced domestically, public goods, externalities, leisure activities and non-market dimensions of welfare are of interest.

Finally, note that there is a comparable problem in Western societies, the imputation of rent for owned accommodation. That is, if one owns a house outright and lives in it, taxable income can be allowed to fall, without a decline in well-being. More generally, this paper highlights the interplay between capital ownership (in this case agricultural productive land), income requirements, and cash expenditure patterns. This is a near-universal equation. 


\section{REFERENCES}

AYADI, M. and C. MULLER, "Unit-Values and Measurement Errors. Evidence fromTunisia," mimeo University of Nottingham, July 2003.

BAILAR, B.A., "Quality Issues in Measurement,” International Statistical Review, 53, 123-139, 1985.

BIEMER, P.P, R.M. GROVES, L.E. LYBERG, N.A. MATHIOWETZ, S. SUDMAN, "Measurement Errors in Surveys," John Wiley, New York, 1991

BLAIZEAU, D. and J.-L. DUBOIS, "Connaître les conditions de vie des ménages dans des pays en voie de développement," Ministère de la coopération et du développement, 1989.

BOOKER, W.,P. SINGH, L. SAVANE, "Household Survey Experience in Africa," Living Standard Measurement Studies, nº, 1980.

CASLEY, D.J. and D.A. LURY, "Data Collection in Developing Countries," Clarendon Press, Oxford, 1987.

CHEVRY, G.-R., "Pratique des enquêtes statistiques," P.U.F., 1962.

DEATON, A., "Quality, Quantity, and Spatial Variation of Price," The American Economic Review, pp 418-430, 1988.

DEATON, A., "Price Elasticities from Survey Data. Extensions and Indonesian Results," Journal of Econometrics, 44, 281-309, 1990.

DEATON, A., "The Analysis of Household Surveys: a Microeconometric Approach to Development Policy," John Hopkins University Press, 1997.

GROOTAERT, C., "Mesure et analyse des niveaux de vie dans les pays en voie de développement: Questionnaire annoté," Living Standard Measurement Studies, Document de travail $\mathrm{n}^{\circ} 24$, 1985.

GROSH, M.E. and J. MUNOZ, "A Manual for Planning and Implementing the Living Standards Measurement Study Survey," Living Standards Measurement Study, Working Paper No. 126, 1996.

MINISTERE DU PLAN DU RWANDA, "Enquête Nationale Budget Consommation 1982-83 en milieu rural. Volume 2. Structure du Budget des ménages," 1986.

MORGAN, J.N., "Survey Research" in J. EATWELL, M. MILGATE, P. NEWMAN, "The new Palgrave: A Dictionary of Economics," 1987, Londres, MacMillan.

MULLER, C., "Estimation des consommations de producteurs agricoles d'Afrique centrale," Economie et Prévision, numéro 105, 1992.

UNITED NATIONS, "Programme de mise en place des dispositifs nationaux d'enquête sur les ménages," Département de la coopération technique pour le développement, New York, 1983. 
UNITED NATIONS, "Manuel des méthodes d'enquêtes sur les ménages," Etudes Méthodologiques, série $\mathrm{F}, \mathrm{N}^{\circ} 31,1986$.

O.C.D.E., "Multi-Purpose Household Surveys in Developing Countries," Paris 1978.

PHILIPSON, T., "Data Markets and the Production of Surveys," Review of Economic Studies, 64, 1997.

SCOTT, C., P.T.A. de ANDRE, R. CHANDER, "Conducting Surveys in Developing Countries," Living Standard Measurement Studies, n5, Octobre 1980.

P. VERNEUIL, "Les enquêtes sur la consommation et le niveau de vie en Afrique. Quelques orientations méthodologiques," Archives et Documents, nº 83, INSEE, juin 1983.

WAHAB, M.A. "Income and Expenditure Surveys in Developing Countries: Sample Design and Execution," Living Standard Measurement Studies, Nª, 1980.

VON BRAUN, J., H. DE HAEN, J. BLANKEN, "Commercialization of Agriculture under Population Pressure: Effects on Production, Consumption, and Nutrition in Rwanda", Research report 85, International Food Policy Research Institute, 1991.

WILLIAMS F.M. and P.C. ZIMMERMAN, "Studies of Family Living in the United States and Other Countries: An Analysis of Materials and Methods," USDA Miscellaneous Publication 223, Washington D.C., USGPO, 1935.

WINTER, G., "Méthodologie des enquêtes niveau de vie en milieu rural africain." ORSTOM, 1970. 